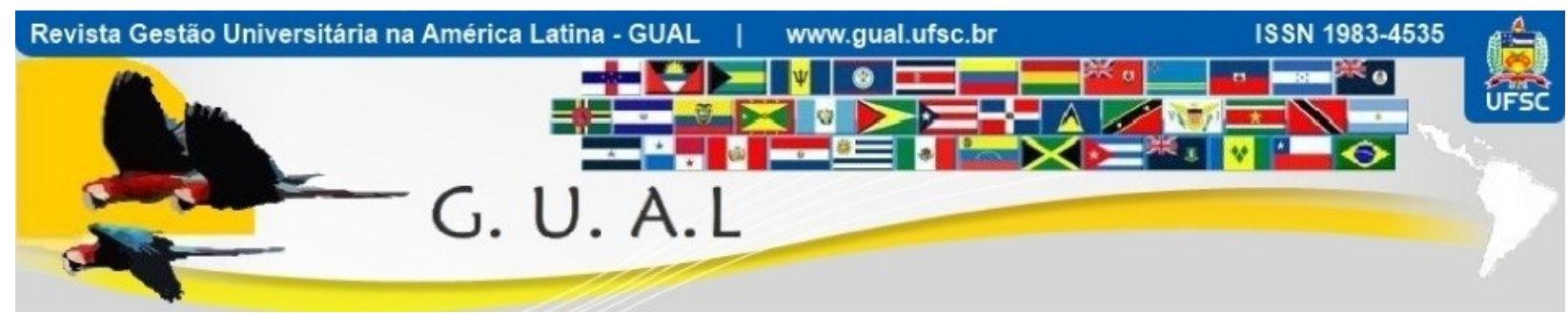

DOI: http://dx.doi.org/10.5007/1983-4535.2016v9n1p177

\title{
MAPEAMENTO DO CLIMA ORGANIZACIONAL EM INSTITUIÇÃO DE EDUCAÇÃO SUPERIOR
}

\section{MAPPING IN AN ORGANIZATIONAL ENVIRONMENT AN INSTITUTION OF HIGHER EDUCATION}

Adelcio Machado dos Santos, Pós-Doutor Universidade Alto Vale do Rio do Peixe - UNIARP adelciomachado@,gmail.com

Joel Haroldo Baade, Doutor Universidade Alto Vale do Rio do Peixe - UNIARP baadejoel@gmail.com

Genéia Lucas dos Santos, Mestre Universidade Alto Vale do Rio do Peixe - UNIARP geneia@,uniarp.edu.br

Edson Donizete Dala Santa, Especialista Universidade Alto Vale do Rio do Peixe - UNIARP dallasanta@,uniarp.edu.br

Scheine Neis Alves da Cruz De Bastiani, Mestre Universidade Alto Vale do Rio do Peixe - UNIARP Faculdade de Tecnologia Senac Caçador scheine.cruz@gmail.com

Recebido em 23/abril/2015

Aprovado em 27/novembro/2015

Sistema de Avaliação: Double Blind Review 


\title{
RESUMO
}

O paradigma constitui o fundamento sobre o qual a comunidade científica desenvolve suas pesquisas, as quais servem de base para o desenvolvimento subsequente da cientificidade. A visão sistêmica possui duas características sistêmicas: a totalidade e o propósito. A primeira estabelece uma visão do conjunto, ou seja, uma organização precisa ser visualizada como um sistema e não separadamente e, o propósito, mostra que é a função que faz a organização, visto que todo sistema possui um objetivo e um propósito para alcançar. O clima organizacional abrange diversos aspectos da conjuntura, que se adiciona reciprocamente em graus diversos, com a modalidade da organização, tecnologia envolvida, as políticas, as metas formais, os regulamentos internos; em suma, fatores estruturais e conjunturais. $\mathrm{O}$ artigo em tela projeta luz sobre o mapeamento do clima organizacional em uma instituição de educação superior. A metodologia empregada combina análise quantitativa e qualitativa através de aplicação de questionários. Conclui-se que o mapeamento do clima organizacional é de fundamental relevância para a tomada de decisão na gestão universitária.

Palavras-chave: Universidade. Clima Organizacional. Gestão Universitária.

\begin{abstract}
The paradigm constitutes the foundationof which the scientific community develop their research, of which work as basis for the subsequent development of scientificity. The systemic view comprises two systemic characteristics: totality and purpose. The first one establishes an overview, that is, an organization needs to be seen as a system, not separately, and the purpose, shows that it is the role that makes the company, considering that every system has a goal and a purpose to reach. The organizational environment comprises several aspects of the conjecture, in which it is added reciprocally in different degrees, according to the organization modality, technology involved, politics, the formal goals, internal regulations; to sum up, structural and conjectural factor. The article itself enlightens the mapping of the organizational environment in an institution of higher education. The methodology combines quantitative and qualitative analysis through questionnaires. We conclude that mapping the organizational climate is of fundamental relevance for decision making in university management.
\end{abstract}

Keywords: University. Organizational Environment. University Management. 


\section{INTRODUÇÃO}

Pádua (1996) define o paradigma como um exemplar, um modelo padrão, sobre o qual é efetuada a construção idealizada que serve para análise ou avaliação de uma realidade concreta. Destarte, um paradigma é uma forma predominante e específica de explicação da realidade em um determinado momento, orientando a prática dos pesquisadores, suas relações com o trabalho, a cultura e organização social. À medida que tem início o aparecimento de anomalias em um paradigma, que comprometem a objetividade e exatidão da pesquisa científica e cuja solução torna-se inviável em termos teóricos, produz-se uma "quebra" de paradigma e sua consequente sucessão por outro.

Assim, em consonância com o magistério de Kuhn (2001), verificam-se revoluções científicas emanadas da crise de fundamentos em um paradigma, produzindo o deslocamento de uma visão predominante até aquele momento e a necessidade de elaboração de novos paradigmas para guiar a pesquisa da comunidade científica. Nesses termos, o desenvolvimento constante das Ciências deve-se às anomalias que conduzem ao falseamento de teorias científicas e às mutações de paradigmas.

Da mesma forma, o clima organizacional dentro das organizações pode ser a afirmação dos paradigmas vigentes ou então o embrião da mudança, que produzirá a quebra paradigmática. Nesses termos, o presente estudo analisou o clima organizacional em uma instituição de ensino superior com o propósito de compreender a sua classificação como afirmação das políticas institucionais ou, antes, a negação destas.

Nas últimas décadas, estabeleceu-se uma realidade atrelada a grandes modificações que, de maneira contínua, vem influenciando os ambientes organizacionais, representação das constantes transformações. Uma delas refere-se aos recursos humanos, constituindo-se em um dos precípuos ativos da organização. Isso significa que entre os diversos recursos que uma organização possui - tecnológicos, financeiros, materiais -, o humano representa, em muitas situações, o diferencial competitivo, porquanto as organizações tornam-se cada vez mais semelhantes, considerando os demais recursos. Em outras palavras, igualam-se dimensão tecnológica, recursos financeiros para investimento, entre outros aspectos, situando-se a vantagem competitiva em seus recursos humanos.

Cumpre salientar dificuldades inerentes ao nascimento da organização cujo mapeamento do clima organizacional se efetua neste artigo. De fato, a Uniarp, gerada em cenário turbulento e instável, visto que se desvinculou de outro projeto estrutural, ainda 
hospeda suspicácias entre os envolvidos no turbulento processo. Destarte, emerge a relevância da avaliação do clima organizacional, visando à formulação e implementação de medidas que melhorem as relações interpessoais, vertical e horizontalmente.

Assim, na medida em que analisa e possibilita compreender a organização com maior profundidade, especialmente no que se refere à percepção das pessoas que nela atuam, sob diferentes óticas, o estudo pretendeu oferecer subsídios para tomadas de decisão mais eficientes e eficazes.

Para a concretização do objetivo proposto, a análise subsequente foi dividida em cinco partes. Inicialmente se aborda a noção de clima organizacional do ponto de visa teórico. Cabe, na continuidade, informar o leitor a respeitos dos procedimentos metodológicos adotados para a realização da pesquisa aqui relatada. No terceiro ponto da abordagem, intitulado Perfil dos profissionais respondentes, descreve o perfil das pessoas que atuam na instituição em foco. Então, faz-se a análise do clima organizacional na organização a partir dos resultados da pesquisa. O texto é finalizado com breves considerações finais, que destacam alguns aspectos da pesquisa e projeta possibilidades a partir dos resultados da pesquisa.

\section{CLIMA ORGANIZACIONAL}

O clima organizacional converteu-se em construto cada vez mais essencial para apresentar as percepções das pessoas em relação às organizações em que trabalham. O clima é um conceito abrangente por ser uma maneira de sintetizar diversas percepções em um pequeno número de dimensões. Posto que o conceito de clima tenda a ser empregado para descrever organizações, o termo também pode ser empregado para distinguir as percepções das pessoas em relação aos grupos ou equipes em que trabalham.

Campos (2002), ainda, lembra que todas as organizações são constituídas de recursos humanos e de recursos materiais. Nelas são produzidos bens e serviços. As organizações são extremamente heterogêneas e diversificadas, de tamanhos, estruturas e objetivos diferentes, não existindo em hipóteses alguma, assim como os indivíduos, duas organizações semelhantes. E uma organização nunca é igual ao longo do tempo. Existem organizações lucrativas ou utilitárias e organizações não-lucrativas ou normativas.

Estudar e identificar o clima organizacional e os mecanismos que afetam os sentimentos dos membros de uma organização é a base para entender como a organização e suas práticas administrativas influenciam o interesse e o comportamento das pessoas. Payne e Pugh (1971) consideram o clima organizacional como o elo conceitual que liga o nível 
individual ao organizacional no sentido de expressar a compatibilidade ou congruência das expectativas, valores e diretrizes formais. Destarte, a importante atenção que tem sido desprendida sobre o conceito de clima organizacional foi uma tentativa para entendimento dos processos pelos quais a estrutura organizacional e estratégias administrativas afetam a motivação e atitudes não somente individuais dos colaboradores, como também do trabalho em equipe. Daí, o nome de clima organizacional dado ao ambiente interno existente entre os membros da organização. O clima organizacional está intensamente relacionado com o grau de motivação de seus participantes.

Quando existe elevada motivação entre os membros, o clima motivacional aumenta e se exprime em relações de satisfação, de animação, interesse, colaboração, entre outros. Entretanto, quando existe baixa motivação entre os membros, seja por frustração ou barreiras à satisfação das necessidades, o clima organizacional tende a arruinar-se, sendo caracterizado por estados de depressão, desinteresse, apatia e insatisfação, podendo, em casos extremos, chegar a estados de agressividade, tumulto e inconformidade, típicos de situações em que os membros se enfrentam claramente com a organização como nos casos de greves e protestos.

O clima organizacional consiste em percepção compartilhada entre os vários protagonistas de uma organização do ambiente interno e do ambiente externo que de algum modo estabelecem os vários comportamentos que são encontrados nas organizações. Estas mesmas pessoas inventam configurações globais do seu ambiente a partir de suas percepções e determinam o clima organizacional.

De acordo com Litwin (1971), o conceito de clima organizacional envolve um quadro mais extenso e maleável da influência ambiental sobre a motivação dos membros da organização. O clima organizacional é a qualidade da propriedade do ambiente organizacional que é compreendida ou experimentada pelos membros da organização e influencia o seu comportamento.

Dessa maneira, o clima organizacional procede da percepção e de sentimento em relação à clareza dos objetivos da organização; clareza da definição das prioridades de trabalho; equilíbrio na dedicação ao trabalho; integração com pessoal de outras áreas; eficiência nos serviços prestados pelos fornecedores internos; atitudes do gerente; qualidade na comunicação; ambiente de amizade; bom relacionamento; conhecimento da empresa, entre outros.

O termo clima organizacional relaciona-se às propriedades motivacionais do ambiente organizacional, isto é, aqueles aspectos do ambiente que levam à provocação de diferentes 
espécies de motivação. Para Atkinson (1964), ele consiste na soma do padrão total de experiências e valores de incentivos que existem em dado conjunto organizacional. É importante lembrar que o fator tempo é acentuado na verificação do clima organizacional uma vez que o clima está diretamente ligado ao ambiente da organização que em determinadas ocasiões apresenta-se estável e, em outros, instável, o que influencia o comportamento das pessoas e suas percepções sobre o ambiente de trabalho.

Ademais disso, o clima organizacional pode ser afetado entre outros, pelos seguintes fatores: segurança no trabalho; normas internas; sistemas de benefícios; relações interpessoais; processo decisório; ambiente físico; objetivos organizacionais; estilo de liderança; cultura; comunicação; seriedade dos dirigentes; recompensas; mudanças; estratégias motivacionais; relações sindicais; governo; tecnologia; legislação.

Conforme Segredo Pérez (2011), merece destaque a valorização do estudo do clima organizacional por se tratar de uma valiosa ferramenta diagnóstica para a gestão, com vistas ao desenvolvimento de instituições mais eficientes e eficazes. Segundo esta autora, o estudo do clima organizacional nas organizações pode ser realizado a partir de cinco dimensões básicas: motivação, liderança, reciprocidade, participação e comunicação.

\section{MATERIAIS E MÉTODOS}

A metodologia de pesquisa adotada consistiu na aplicação de questionário estruturado, com possibilidade de comentários adicionais ao final do preenchimento. Tanto as alternativas assinaladas nas diferentes questões como os comentários foram considerados na análise dos dados. O questionário possuía quarenta e três questões, sendo que as primeiras cinco questões serviram para a caracterização do perfil do profissional e as demais abordaram aspectos referentes ao clima organizacional propriamente dito.

O questionário foi remetido à totalidade da população pesquisa, ou seja, 366 (trezentos e sessenta e seis) sujeitos, por meio de correio eletrônico - Email. Todos os colaboradores da instituição foram solicitados a participarem da pesquisa, seja das áreas administrativas como das áreas acadêmicas. Deste total, foram devolvidos 133 (cento e trinta e três) questionários preenchidos, o que equivale a $36,34 \%$ do total de sujeitos.

Os dados foram analisados no seu conjunto, mas fez-se a distinção entre áreas administrativa e acadêmica quando pertinente. Os comentários feitos nas questões abertas do questionário foram contemplados ao longo da discussão e não em bloco especial, sendo que a 
referência do questionário é feita pela letra "Q" e o respectivo número identificador (Ex.: Q103).

\section{PERFIL DOS PROFISSIONAIS RESPONDENTES}

Em relação ao perfil dos profissionais que responderam ao questionário, aspecto contemplado nas cinco primeiras questões do instrumento utilizado para a coleta de dados, obteve-se os seguintes resultados. A maioria dos questionários foi respondido por mulheres $(61,83 \%)$. Atuam na instituição preponderantemente pessoas entre vinte e um (21) e cinquenta (50) anos de idade. Segundos dados coletados, 31,3\% têm entre trinta e um (31) e quarenta (40) anos. Há ainda $27,48 \%$ de pessoas entre vinte e um (21) e trinta (30) anos e o mesmo percentual de pessoas entre quarenta e um (41) e cinquenta (50) anos. Apenas 10,69\% tem mais de cinquenta (50) e 3,05\% menos de vinte (20) anos de idade.

O nível de escolaridade dos respondentes da pesquisa está representado no gráfico 1 . Os dados evidenciam que o questionário foi majoritariamente respondido por profissionais com pós-graduação.

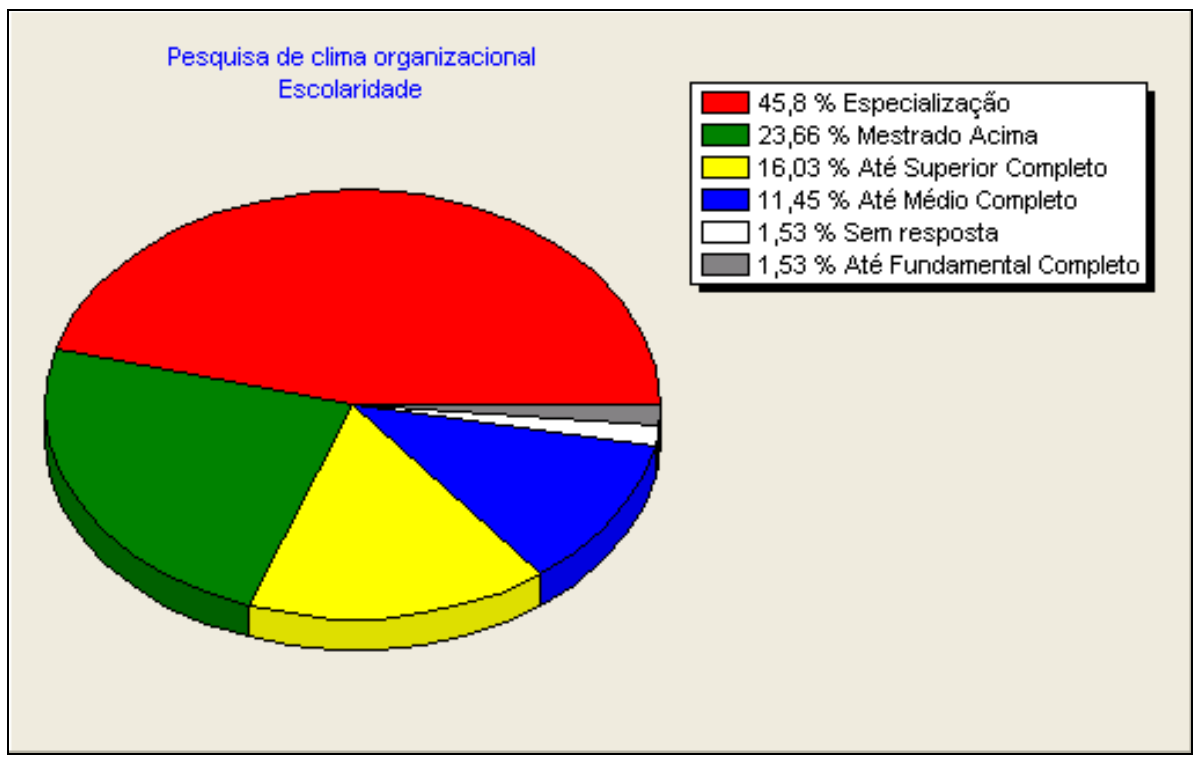

Gráfico 1 Nível de escolaridade.

Fonte: Dados da pesquisa.

Os respondentes se caracterizam por atuarem mais do que cinco anos na instituição $(52,67 \%)$, sendo que 32,06\% possuem tempo de atuação profissional superior a dez (10) anos. Além disso, 9,92\% dos profissionais estão na organização entre três (3) e cinco (5) anos; $25,95 \%$ ainda estão entre um (1) e três (3) anos e apenas $11,45 \%$ estão na instituição há 
menos de um (1) ano. Por outro lado, pode-se inferir que pessoas que estão entre um (1) e três (3) e há mais de dez (10) anos na organização estão mais predispostas a atenderem a solicitações além das suas rotinas profissionais corriqueiras $(58,01 \%$ dos respondentes), pois foi de quem mais se obteve resposta ao questionário.

A pesquisa foi respondida por $64,12 \%$ de profissionais que atuam na área acadêmica, ou seja, por docentes e por $6,87 \%$ de pessoas que atuam simultaneamente nas áreas acadêmica e administrativa. Apenas $27,48 \%$ dos respondentes atuam apenas na área administrativa da universidade. Em dois questionários não foi informada a área de atuação do respondente.

A partir disso, passa-se a analisar o clima organizacional da instituição no próximo ponto.

\section{MAPEAMENTO DO CLIMA ORGANIZACIONAL DA UNIARP EM 2012}

A caracterização do clima organizacional da Uniarp exposta a seguir teve por base as trinta e oito (38) questões do questionário respondidas por 133 (cento e trinta e três) profissionais da instituição conforme perfil descrito no item anterior. Ao longo da análise, como já referido, se faz a inserção dos comentários das questões abertas. Chamou a atenção que $61,07 \%$ dos respondentes fez comentários no questionário.

A primeira questão desse bloco de perguntas indagou sobre a valorização pelo esforço empreendido em favor da instituição. $66,41 \%$ dos profissionais consideram a valorização pelo esforço Boa (32,82\%), Muito boa $(19,85 \%)$ e Ótima $(13,74 \%)$. Já 37,07\% consideram a valorização Ruim (6,11\%), Regular (24,43\%) e Inexistente (1,53\%). Em dois (2) questionários esta pergunta não foi respondida. Essa tendência também apareceu nos comentários feitos no questionário 033: "Está no caminho certo, tem que continuar valorizando os colaborados e seguir em frente." Contudo, treze comentários enfatizaram a necessidade de maior valorização das pessoas que atuam na instituição, seja através da remuneração (Q060, Q071), de elogios (Q054, Q100, Q121, Q109), formação continuada (Q055, Q060) e/ou através da concessão de mais benefícios como plano de saúde em que haja a coparticipação da instituição (Q109).

A seguir, indagou-se pelas possibilidades de crescimento na organização, sendo que $58,78 \%$ dos profissionais as consideram Boa (33,59\%), Muito boa $(16,79 \%)$ e Ótima $(8,4 \%)$. $39,69 \%$ das pessoas, por outro lado, consideram que as possibilidades de crescimento são Ruins $(6,11 \%)$, Regulares $(25,95 \%)$ ou Inexistentes $(7,63 \%)$. Também nesta questão houve 
dois questionários sem resposta. A esse respeito, Q060 enfatizou que, caso exercesse um cargo de liderança, se "Preocuparia com as necessidades de cada setor, disponibilizaria treinamentos, cursos de aperfeiçoamento, oportunizaria o crescimento do funcionário no setor valorizando-o financeiramente e profissionalmente." Ou seja, reconhece-se que há possibilidades de crescimento, mas ao mesmo tempo almeja-se maior comprometimento da instituição no sentido de viabilizar a formação necessário para que isso ocorra. Nos comentários essa questão foi recorrente (Q004, Q007, Q009, Q029, Q043, Q055, Q061, Q062, Q065 - “Investimento em capacitação”, Q093 - “auxilio capacitação”, Q094, Q102 "Incentivo aos professores fazer mestrado e doutorado"). Por essa razão, quanto aos incentivos oferecidos pela instituição para a qualificação profissional, 54,96\% dos respondentes os consideram Bons (25,19\%) Muito bons (19,85\%) e Ótimos (9,92\%). Em contrapartida, 45,04\% consideram os incentivos Ruins (17,56\%) e Regulares (27,48\%). Nesta questão não houve omissões ou afirmação de inexistência de incentivos para a qualificação profissional.

Também se perguntou pelos treinamentos e capacitações oferecidos pela instituição. Segundos os respondentes, as iniciativas da instituição nesse tocante são insuficientes $(40,46 \%)$ ou inexistentes $(38,17 \%)$, totalizando $78,63 \%$. Apenas $21,37 \%$ dos profissionais considerou os treinamentos e capacitações suficientes. Contudo, quando perguntados pela qualidade dos treinamentos e capacitações oferecidos, 63,35\% considerou que eles eram Bons (37,4\%), Muito bons (16,79\%) e Ótimos (9,16\%). Apenas $15,27 \%$ dos respondentes considerou que os treinamentos e capacitações eram Ruins (4,58\%) e Regulares (10,69\%). Outrossim, 21,37\% das pessoas deixam de responder a esta questão. Isso pode ser indício de que a instituição tem potencial para o oferecimento de bons treinamentos e capacitações, mas ainda o faz em número aquém das expectativas dos profissionais que nela atuam.

Outro tema abordado disse respeito à remuneração. O gráfico 2 apresenta os resultados sobre a questão que indagou pela relação entre o salário recebido e a função exercida. 


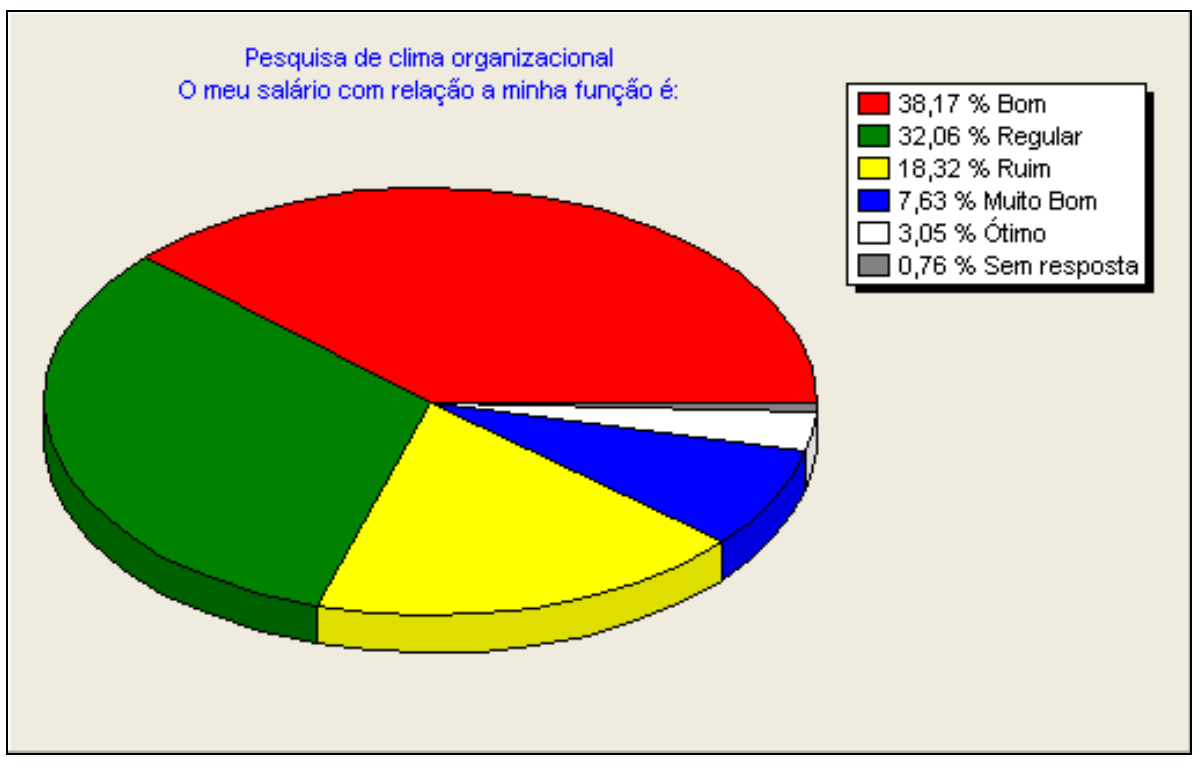

Gráfico 2 Salário em relação à função.

Fonte: Dados da pesquisa.

Conforme demonstrado, $48,85 \%$ dos respondentes consideraram o seu salário Bom, Muito bom e Ótimo. Por outro lado, 50,28\% das pessoas consideraram a sua remuneração em relação à função exercida Ruim ou Regular. Uma pessoa não respondeu a esta questão. Contudo, a questão foi percebida de forma diversa pelos setores administrativo e acadêmico, conforme apresentado na tabela 1 a seguir.

Tabela 1 Percepção da remuneração pelos setores administrativo e acadêmico.

\begin{tabular}{lcccccc}
\hline \multicolumn{1}{c}{ Setor } & Ótimo & Muito bom & Bom & Regular & Ruim & $\begin{array}{c}\text { Sem } \\
\text { resposta }\end{array}$ \\
\hline $\begin{array}{l}\text { Acadêmico } \\
\begin{array}{l}\text { Técnico- } \\
\text { administrativo }\end{array}\end{array}$ & $3,57 \%$ & $7,14 \%$ & $40,48 \%$ & $27,38 \%$ & $20,24 \%$ & $1,19 \%$ \\
\hline
\end{tabular}

Fonte: Dados da pesquisa.

Conforme os dados da tabela 1 , há uma insatisfação maior com a remuneração nos setores técnico-administrativos, em que $61,11 \%$ dos respondentes manifestou a percepção quanto ao próprio salário como Regular ou Ruim. Na área acadêmica, por sua vez, este percentual foi de 47,62\%. Por outro lado, 85,25\% (Bom, Muito bom e Ótimo) dos profissionais reconheçam a exatidão dos valores informados em suas folhas de pagamento. Nos comentários às questões abertas, a remuneração foi referida 31 (trinta e uma) vezes, mas especialmente vinculada ao debate sobre a necessidade de um plano detalhado de cargos e salários (Q002, Q006, Q010, Q042, Q043, Q048, Q096, Q109, Q112, Q118 e outros). A 
melhoria salarial especificamente, por sua vez, foi mencionada apenas 9 (nove) vezes (Q051, Q062, Q064, Q065, Q075, Q081, Q090, Q106, Q131).

Nos comentários, a relação entre a qualidade da remuneração e o nível de motivação dos profissionais da instituição também foi mencionado. Sendo a motivação uma das dimensões básicas no estudo do clima organizacional conforme Segredo Pérez (2011), ela merece atenção especial. Q006, por exemplo, comenta: "Plano de cargos e salários coerentes não uns ganhando muito sem muito trabalho e outros ganhando pouco e fazendo muito."

O tratamento dispensado pelo gestor direto também foi avaliado pelo questionário aplicado. Ele foi considerado Bom $(49,62 \%)$ e Excelente $(38,93 \%)$ por $88,55 \%$ das pessoas que participaram da pesquisa. $9,16 \%$, por seu turno, consideraram o tratamento recebido como Ruim e Regular. Esta questão não foi respondida por 2,29\% dos participantes. Com relação ao tratamento dispensado por gestores de outras áreas da instituição, 78,63\% dos participantes afirmou que ele é Bom (62,6\%) e Excelente (16,03\%). Enquanto 14,51\% disse que o relacionamento é Ruim (1,53\%) e Regular (12,98\%). Uma pessoa não respondeu a questão e 6,11\% afirmou não ter relacionamento com gestores de outras áreas. Por fim, quanto ao tratamento dispensado pela diretoria da instituição, 74,79\% dos participantes consideram ele Bom (56,49\%) e Excelente (18,32\%). 14,51\% das pessoas consideraram o tratamento dispensado pela diretoria como Ruim $(3,82 \%)$ e Regular $(10,69 \%)$. Uma pessoa não respondeu a esta questão e $9,92 \%$ dos participantes afirmaram não ter relacionamento com a diretoria da instituição. Ressalta-se, assim, que a relação de liderança na instituição analisada, nos diferentes níveis, foi um dos aspectos mais positivamente avaliados pelos participantes. Também não foram feitos comentários adicionais ao tema.

$\mathrm{O}$ aspecto seguinte a ser abordado disse respeito aos relacionamentos com os colegas de trabalho. O relacionamento com os colegas de trabalho foi considerado Excelente $(49,62 \%)$ e Bom $(44,27 \%)$ por $93,89 \%$ dos participantes. Apenas 4,58\% respondeu que este relacionamento é satisfatório e 1,53\% não respondeu a questão. Quanto ao companheirismo e integração entre as pessoas da instituição a resposta foi menos unânime. 70,23\% dos respondentes considerou o nível de companheirismo Bom (40,46\%), Muito bom (17,56\%) e Ótimo (12,21\%). Ao passo que 29,78\% das pessoas afirmaram que o nível de companheirismo é apenas Regular (26,72\%), Ruim (1,53\%) ou não responderam a questão $(1,53 \%)$. Outro aspecto nesse quesito foi a classificação do grau de cooperação e espírito de equipe no ambiente de trabalho, que foi considerado Bom (33,59\%), Muito bom (22,9\%) ou Ótimo (16,03\%) e Ruim (1,53\%) ou Regular (25,19\%) por $72,52 \%$ e $26,72 \%$ dos 
participantes, respectivamente. Uma pessoa não respondeu à pergunta. Também quanto ao respeito entre os colaboradores constatou-se que $80,15 \%$ deles consideram-se Satisfeitos $(72,52 \%)$ ou Muito satisfeitos $(7,63 \%)$ e apenas $8,4 \%$ consideram-se insatisfeitos a esse respeito. $11,45 \%$ dos participantes declararam-se indiferentes ou não responderam a questão. Os dados evidenciaram um ambiente propício para o desenvolvimento de trabalhos em equipe e grande grau de reciprocidade entre os colaboradores, o que também contribuiu para a manutenção do grau motivacional.

Com relação à realização do próprio trabalho, todos os respondentes consideram-no Bom (29,77\%), Muito bom (52,67\%) ou Ótimo (17,56\%). Além disso, 92,37\% deles consideram-se Satisfeitos (67,94\%) ou Muito satisfeitos $(24,43 \%)$ com a função que exercem. Apenas $7,64 \%$ dos participantes declararam-se Indiferentes $(6,11 \%)$ ou Insatisfeitos $(1,53 \%)$. Da mesma forma, com relação aos objetivos e metas inerentes a sua função, $88,55 \%$ dos participantes afirmara-se Satisfeitos (74,05\%) ou Muito satisfeitos (14,5\%). 11,44\% disseram estar Insatisfeitos $(5,34 \%)$, Indiferentes $(5,34 \%)$ ou não responderam a questão $(0,76 \%)$. Entendeu-se que estes itens contribuíram para a elevação do grau de motivação dos respondentes, bem como auxiliaram para o sentimento de participação no destino da organização.

No gráfico 3, a seguir, apresentam-se os dados em relação ao uso de benefícios concedidos pela instituição.

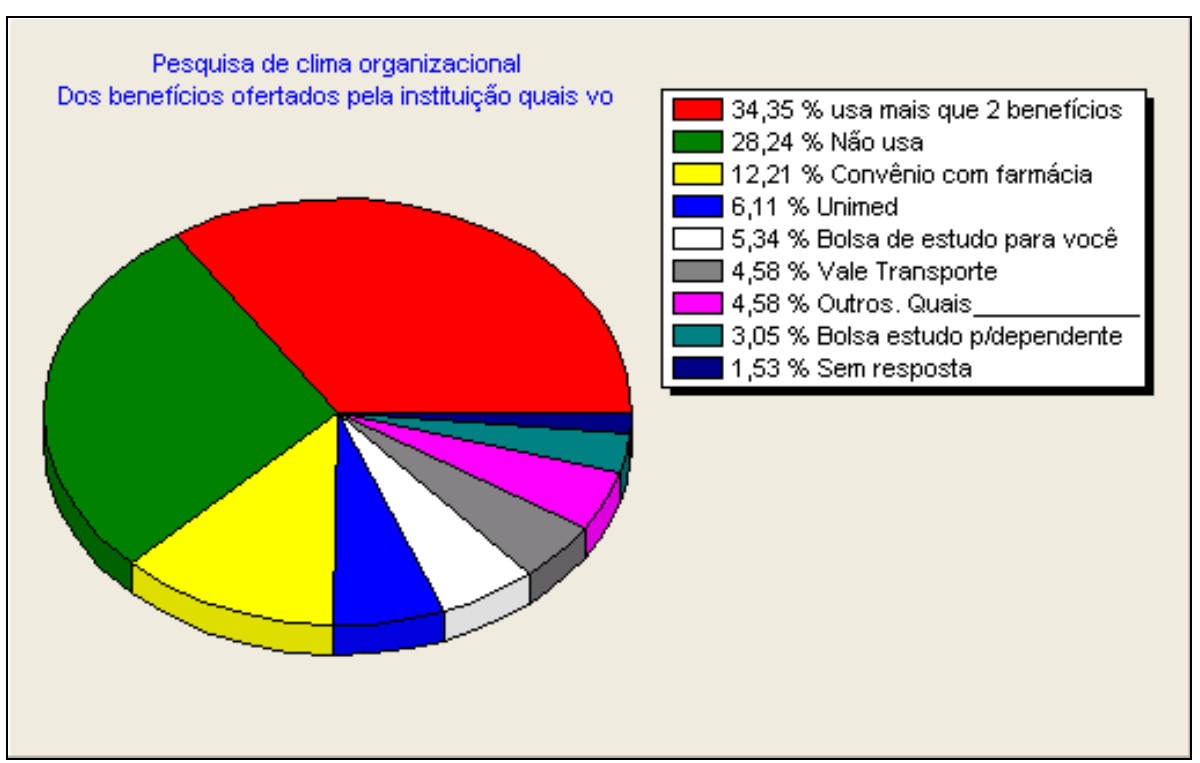

Gráfico 3 Uso dos benefícios ofertados pela instituição.

Fonte: Dados da pesquisa. 
A esse respeito ainda, $64,88 \%$ dos respondentes declararam-se Satisfeitos $(46,56 \%)$ e Muito satisfeitos $(18,32 \%)$ com os benefícios concedidos pela instituição. Contudo, 19,08\% deles não responderam à questão ou disseram-se Insatisfeitos (5,34\%) e Muito insatisfeitos $(0,76 \%) ; 9,92 \%$ dos respondentes ainda foram indiferentes. Desse modo, entende-se que houve falta de unanimidade quanto aos benefícios concedidos pela instituição, sendo esta uma questão que carece de estudos mais detalhados, levando em conta também que quase um terço dos respondentes não utiliza-se dos benefícios (28,24\%). Contraditoriamente, os comentários nas questões abertas referem recorrentemente a necessidade de a instituições oferecer mais benefícios aos seus colaboradores, seja para a capacitação profissional, participação em eventos promovidos pela instituição e na forma de bolsas de estudo para o próprio funcionário ou então para seus familiares. Houve, por exemplo, sete manifestações de solicitação de plano de saúde, sendo este um benefício já oferecido pela instituição. Considerando o fato de que um percentual expressivo manifestou deficiência na comunicação interna da instituição, o que se aborda mais abaixo, é preciso perguntar pelas reais causas de tais reivindicações. A discrepância com relação aos benefícios contribui também para a diminuição do grau motivacional e para a percepção do nível de participação dos respondentes. Em Q108 fala-se o seguinte: "Estamos iniciando um novo tempo na Universidade com muitas ações em andamentos. Novos cursos, novo "olhar" na busca do crescimento da Instituição, mas temos que envolver as pessoas (funcionários), investir na qualificação, implantar programas de alguns benefícios que hoje não são contemplados cujo objetivo é melhorar a qualidade de vida."

Da mesma forma, o grau de segurança e estabilidade na instituição é percebido de forma diversa pelos respondentes, conforme apresentado no gráfico 4. 


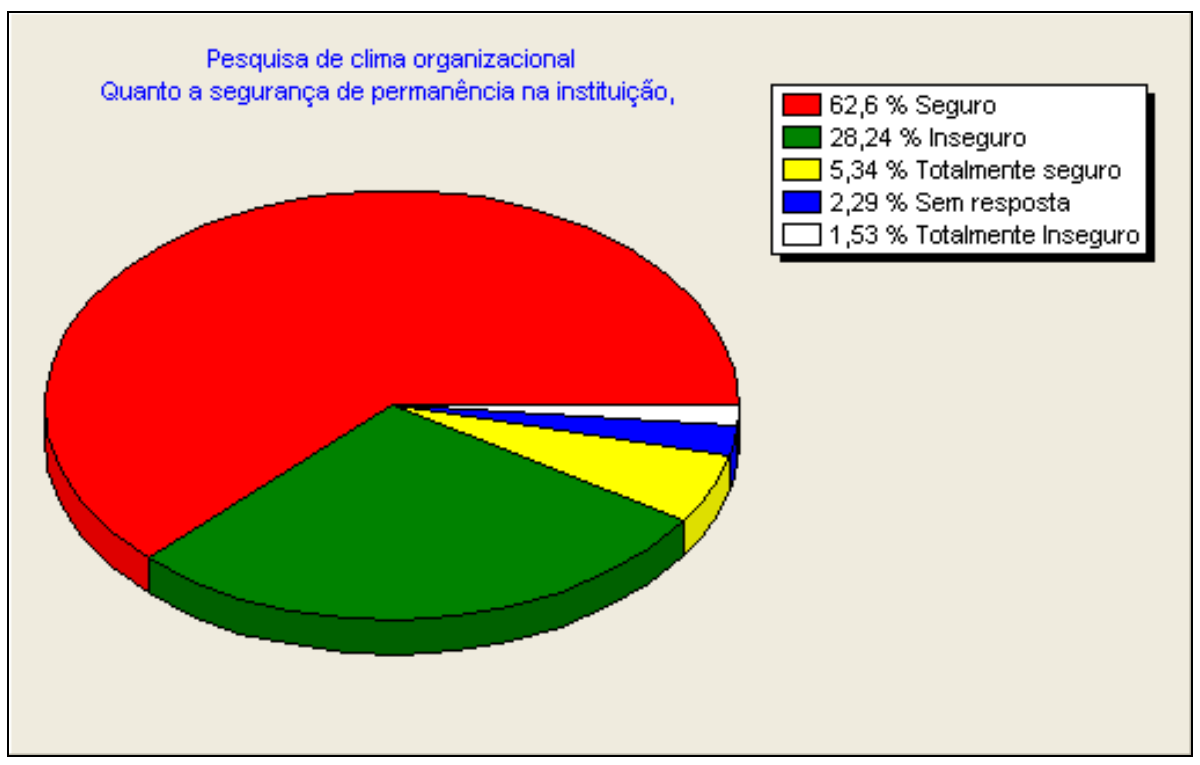

Gráfico 4 Segurança de permanência na instituição. Fonte: Dados da pesquisa.

Chama a atenção que 29,77\% dos respondentes sentem-se Inseguros ou Totalmente inseguros e ainda 2,29\% não responderam à questão. Nesse aspecto, apenas estudos comparativos com outras instituições permitiriam avaliar esta questão mais precisamente. De qualquer forma, este pode ser um aspecto a ser trabalhado na instituição com vistas à ampliação do grau de estabilidade e segurança dos seus colaboradores. A segurança na função também é referida nos comentários às questões abertas. Uma questão recorrente disse respeito à necessidade de implantação de um plano mais detalhado de cargos e salários, com mérito para desempenho na função (total de 14 menções). Também foi pertinente o comentário em Q092, segundo o qual: "Deveria ter um sistema de classificação ou de meritocracia, [...] o professor só sai da disciplina caso tenha uma avaliação ruim, caso contrário não pode ser trocado professor, nem pela reitoria."

A questão seguinte indagou pela satisfação em relação à comunicação na instituição. Do total de respostas obtidas, $53,43 \%$ foram manifestações de satisfação ou muita satisfação. Contudo, 35,88\% manifestaram-se Insatisfeitos ou Muito insatisfeitos, indicando que este é um aspecto que merece atenção dos gestores e gestoras. Além disso, 9,92\% se manifestaram indiferentes e $0,76 \%$ não respondeu à questão. Nesse aspecto, se perguntou também pela relação de diálogo entre os gestores(as) e liderados(as), ao que 58,02\% se manifestaram Satisfeitos e 6,11\% Muito satisfeitos. Apenas 16,79\% se disseram Insatisfeitos e 1,53\% Muito insatisfeitos. Chamou a atenção que 16,03\% expressaram indiferença quanto à relação de diálogo com os seus gestores. Comparativamente, percebeu-se que a comunicação e diálogo 
estão relacionadas com o nível hierárquico, quanto mais próxima a relação dentro da hierarquia, mais os colaboradores e colaboradoras tendem a perceber a efetividade da comunicação e do diálogo. Isso também ficou evidenciado na pergunta sobre o recebimento de informações do gestor e da gestora para o desempenho da função. 94,66\% disseram receber informações Sempre (34,35\%), Frequentemente (31,3\%) e Às vezes (29,01\%).

A importância da relação com o superior imediato também ficou evidenciada na pergunta sobre o recebimento de feedback, sendo que 55,73\% dos respondentes o recebem dele. Apenas 19,08\% dos participantes recebem feedback dos seus colegas de trabalho e percentual igual afirmou nunca receber feedback. 4,58\% ainda disseram receber feedback das pessoas do departamento de Recursos Humanos da instituição e 1,53\% não responderam a questão.

A pesquisa mostrou que o Email é a forma predominante de comunicação, sendo que $32,06 \%$ dos respondentes afirmaram receber informações somente por este meio de comunicação. Além disso, 45,04\% disseram receber as informações por mais de dois meios, o que inclui também o Email. Apenas 10,69\% manifestaram receber as informações da chefia imediata, Intranet $(7,63 \%)$ ou que raramente recebem informações $(3,05 \%)$.

Um aspecto fundamental da pesquisa sobre o clima organizacional na instituição disse respeito aos problemas do dia a dia e as suas tratativas. 69,46\% das pessoas afirmaram estar Satisfeitas $(61,83 \%)$ ou Muito satisfeitas $(7,63 \%)$ a esse respeito. 15,27\%, por outro lado, se disseram Insatisfeitos e 0,76\% Muito insatisfeitos. 14,5\% forma Indiferentes (12,21\%) ou não responderam (2,29\%). A pesquisa também perguntou sobre a percepção em relação à expressão de opiniões a respeito da instituição. A isso, 38,17\% dos respondentes disseram que Às vezes são ouvidos, $25,19 \%$ que Geralmente são ouvidos e $16,79 \%$ que Raramente são ouvidos. Ainda 18,32\% manifestaram não se sentirem a vontade para manifestarem as suas opiniões e 1,53\% não responderam a questão. A questão dá indícios de um anseio por maior participação através da manifestação de opiniões. As duas questões contribuíram para a elevação do grau de reciprocidade.

Nos comentários feitos nas questões abertas, a necessidade de diálogo, cooperação e participação mais efetiva também foi referida. No Q001, por exemplo, mencionou-se: "Promoveria encontros (reuniões) de trabalho para ouvi-los, e encaminhar questões importantes. Apresentaria o objetivo da instituição e os convidaria para olhar para o mesmo objetivo." De forma semelhante referiu o respondente do Q010: "Discussões abertas acerca de todos os temas importantes, permitindo, assim, construções de decisões 'não impostas'" e 
Q041: “Ouvir mais, falar menos e agir de forma coerente. Administração participativa.”. A reivindicação de uma maior possibilidade de participação ainda é referida em mais comentários, quando se fala em diálogo (Q043), canal de comunicação (Q052), circulação da informação (Q060), comunicação clara e frequente (Q061), ouvir todos (Q071), contato (Q076), envolvimento (Q088), escuta (Q094), voto e opinião (Q110), reuniões de integração (Q115) etc. Assim, a partir dos dados, infere-se que há perda de motivação, reciprocidade, participação e comunicação, ou seja, quatro das cinco dimensões básicas do clima organizacional referidas por Segredo Pérez (2011).

A tabela 2 sintetiza os resultados de quatro questões sobre as condições gerais de trabalho.

Tabela 2 Condições gerais de trabalho.

\begin{tabular}{|c|c|c|c|c|c|c|}
\hline Questão/Respostas & $\begin{array}{c}\text { Muito } \\
\text { satisfeito }\end{array}$ & Satisfeito & Indiferente & Insatisfeito & $\begin{array}{c}\text { Muito } \\
\text { insatisfeito }\end{array}$ & $\begin{array}{c}\text { Sem } \\
\text { resposta }\end{array}$ \\
\hline Horário de trabalho & $27,48 \%$ & $47,33 \%$ & $9,16 \%$ & $14,5 \%$ & - & $1,53 \%$ \\
\hline $\begin{array}{l}\text { Infraestrutura do } \\
\text { local de trabalho }\end{array}$ & $9,16 \%$ & $53,44 \%$ & $7,63 \%$ & $25,95 \%$ & $3,82 \%$ & - \\
\hline $\begin{array}{l}\text { Acessibilidade da } \\
\text { infraestrutura }\end{array}$ & $7,63 \%$ & $28,24 \%$ & $36,64 \%$ & $23,66 \%$ & $2,29 \%$ & $1,53 \%$ \\
\hline $\begin{array}{l}\text { Recursos } \\
\text { materiais no local } \\
\text { de trabalho }\end{array}$ & $13,74 \%$ & $31,3 \%$ & $32,06 \%$ & $22,14 \%$ & - & $0,76 \%$ \\
\hline $\begin{array}{ll}\text { Condições } & \text { de } \\
\text { segurança } & \text { da } \\
\text { instituição } & \end{array}$ & $7,63 \%$ & $46,56 \%$ & $31,3 \%$ & $12,98 \%$ & $1,53 \%$ & - \\
\hline Média & $13,13 \%$ & $41,37 \%$ & $23,36 \%$ & $19,85 \%$ & $2,55 \%$ & $1,27 \%$ \\
\hline
\end{tabular}

Fonte: Dados da pesquisa.

Conforme os dados da tabela 2, a percepção geral em relação ao horário de trabalho, infraestrutura do local de trabalho, acessibilidade da infraestrutura, recursos e materiais e condições de segurança do local de trabalho oscilam, preponderantemente, entre satisfação, indiferença e insatisfação. A média dos percentuais, contudo, indica que 54,5\% dos respondentes estão Muito satisfeitos (13,13\%) ou Satisfeitos (41,37\%) em relação às questões analisadas. Nessas questões, não foi percebida uma diferença significativa entre os setores técnico-administrativo e acadêmico. 
As três últimas questões do questionário indagaram pelo conhecimento da estrutura educacional da instituição no que diz respeito a salas de aula, laboratórios, clínicas, núcleos etc.; pela imagem geral da instituição; e pelo que diria se alguém indagasse por informações a respeito de trabalhar na instituição.

Quanto à primeira questão, 78,63\% dos respondentes afirmaram ter conhecimento da estrutura educacional da instituição e 9,16\% manifestaram a necessidade de atualizarem o seu conhecimento. 5,34\%, contudo, disseram não conhecer a estrutura e 6,87\% externaram interesse em conhecer. Conforme os dados levantados, há um percentual expressivo de pessoas $(12,21 \%)$ que não tem conhecimento da estrutura educacional da instituição, indicando a necessidade de ações nesse sentido.

Em relação à imagem geral da instituição, sob o ponto de vista do respondente, $80,15 \%$ das respostas sinalizaram que esta é Ótima $(11,45 \%)$, Muito boa $(21,37 \%)$ e Boa $(47,33 \%)$, ao passo que $18,32 \%$ consideram a imagem apenas regular e $1,53 \%$ a consideram ruim.

Por fim, se indagou sobre o que diria a alguém que solicitasse informações sobre trabalhar na instituição. 64,89\% dos participantes da pesquisa disseram Bom e 26,72\% que é Ótimo trabalhar na instituição. 6,87\% dos respondentes consideram que é Difícil trabalhar na instituição e 1,53\% não responderam à pergunta. Ou seja, 91,61\% das pessoas consideram Bom ou Ótimo trabalhar na instituição e a recomendariam a outrem.

\section{CONSIDERAÇÕES FINAIS}

Conclui-se, a partir da análise empreendida, que o clima organizacional na organização é bom, mas possui deficiências especialmente nas dimensões motivação, participação e comunicação.

Embora um percentual expressivo dos profissionais da instituição esteja satisfeito com a valorização que lhes é dada no desempenho de suas funções, há um número expressivo que anseia por maior valorização em relação aos esforços que empreendem em prol da organização. Aliado a isso, anseia-se por mais oportunidades de crescimento dentro da organização e por incentivo e auxílio para a qualificação profissional, que pode ser externa ou internamente através de programas de treinamento e qualificação. Como as ações empreendidas nesse quesito foram consideradas boas pelos respondentes, entende-se que a concretização de ações internas com vistas à qualificação profissional seria bem-vinda, satisfazendo inclusive anseios por maior valorização dentro da organização. 
Os profissionais da instituição estudada também têm expectativas de uma melhor remuneração ente relação à função que desempenham, embora reconheçam a exatidão dos valores informados em suas folhas de pagamento. Mesmo que não seja decisivo, este fator afeta a dimensão motivacional.

A relação com os gestores da instituição em todos os níveis foi avaliada positivamente, embora haja algumas pessoas que não estejam satisfeitas com o tratamento que lhe é dispensado pelos seus gestores diretos, pelos gestores de outros setores e/ou pelos membros da diretoria da instituição. A relação entre os colegas de trabalho, por seu lado, foi avaliada bem mais positivamente, revelando a existência de um ambiente com potencial de cooperação e coleguismo. Embora haja a necessidade de mais estudos a esse respeito, os dados evidenciaram que este é uma característica que ainda podem ser "explorada" e potencializada na instituição.

Outro ponto a ser analisado em mais detalhes diz respeito à concessão de benefícios e o elevado percentual de colaboradores que sentem-se inseguros quanto à carreira profissional. Reconhece-se que na sociedade atual os níveis de estabilidade profissional não são equivalentes aos de outros momentos históricos, mas a insegurança afeta o nível motivacional e, consequentemente, o desempenho do profissional. A segurança também está, indubitavelmente, relacionada à qualificação, que é fator chave nas instituições de educação superior.

Por fim, ficou evidenciado que há expressivo grau de reivindicação por maior participação na condução dos destinos da instituição. Não houve evidência quanto a isto, mas a deficiência nos processos de comunicação internos podem ter contribuído para a proliferação desse sentimento. Por outro lado, a democratização dos processos decisórios, especialmente no âmbito da educação superior de natureza pública e comunitárias, precisa ser destacada. Isso afetou especialmente as dimensões de motivação e participação, que devem tornar-se alvo de atenção especial dos gestores.

\section{REFERÊNCIAS}

ATKINSON, J. W. An Introduction to Motivation. New York: American Book-Van Nostrand-Reinhold, 1964.

CAMPOS, Celso. A organização inconformista: como identificar e transformar mentes revolucionárias em um diferencial competitivo. 2. ed. rev. Rio de Janeiro: FGV, 2002. 
KUHN, Thomas. A estrutura das revoluções científicas. 6. ed. São Paulo: Perspectiva, 2001.

LITWIN, George H. Climate and Motivation: an experience study. EUA: Prentice-Hall, 1971.

PÁDUA, Elisabete Matallo Marchesini de. Metodologia de pesquisa: abordagem teóricoprática. Campinas: São Paulo, 1996.

PAYNE, R.; PUGH, D. S. Organizations as psychological environments. In: WARR, P. B. (Org.). Psychology at work. Harmondsworth: Penguin, 1971, p. 374-402.

SEGREDO PEREZ, Alina María. La gestión universitaria y el clima organizacional. Educ Med Super [online]. v.25, n.2, p. 164-177, jun. 2011. Disponível em:

$<$ http://scielo.sld.cu/scielo.php?script=sci_arttext\&pid=S0864-

$21412011000200013 \& \operatorname{lng}=\mathrm{es} \& \mathrm{nrm}=\mathrm{iso}>$. Acesso em: 12 nov. 2014. 